\title{
PARCERIAS ENTRE ESTADO E ORGANIZAÇÕES DA SOCIE- DADE CIVIL: ANÁLISE DO SEU ESPAÇO REGULATÓRIO
}

\author{
PARTNERSHIPS BETWEEN THE STATE AND ORGANIZATIONS OF \\ CIVIL SOCIETY: AN ANALYSIS OF A FRAGMENTED REGULATORY \\ SPACE
}

\author{
Natasha Schmitt Caccia Salinas"
}

\begin{abstract}
RESUMO
Este artigo tem por objetivo descrever e analisar a formação e desenvolvimento do espaço regulatório das parcerias entre Estado e Organizações da Sociedade Civil no Brasil. O conceito teórico de "espaço regulatório" é utilizado para representar metaforicamente a relação dinâmica entre normas, instituições e agentes - reguladores e regulados - em determinado tempo e espaço. Nesse artigo, a metáfora do espaço regulatório é utilizada para descrever e explicar a pluralidade de regimes jurídicos que surgiram nas últimas décadas para reger as parcerias entre Estado e Organizações do terceiro setor no Brasil. A fragmentação desse espaço regulatório foi provocada por disputas entre organizações da sociedade civil e atores estatais sobre as regras que deveriam reger essas parcerias. Diante da impossibilidade de se atingir um consenso sobre as normas que deveriam reger essas parcerias, surgiram regimes legais distintos para atender aos múltiplos interesses em jogo. Este artigo descreve esse processo de fragmentação do espaço regulatório a partir da análise de fontes primárias, com destaque para a legislação e suas correspondentes exposições de motivos, bem como depoimentos daqueles que marcaram a construção do espaço regulatório das parcerias entre Estado e Organizações da Sociedade Civil. Além disto, o artigo revisita fontes secundárias, especialmente trabalhos acadêmicos sobre a criação de regimes jurídicos de parcerias. Este artigo contribui para o debate sobre parcerias entre Estado e Organizações da Sociedade Civil na medida que explica seu ambiente legal a partir das lógicas institucionais e das forças sociais que o regem.
\end{abstract}

\begin{abstract}
This paper describes and analyses the processes of formation and development of the regulatory space of the partnerships between the State and Organizations of Civil Society in Brazil. The theoretical concept of "regulatory space" is used as a metaphor to represent the dynamic relationship between statutes and institutions that have an influence on certain stakeholders and activities in a given time and space. In this paper, the metaphor of the regulatory space is used to describe and explain the plurality of legal regimes that have emerged in the past decades to govern the partnerships between the State and third sector organizations in Brazil. The fragmentation of the regulatory space was caused by disputes between civil society organizations and state actors over the rules that should govern these partnerships. Since it was impossible to reach consensus over these rules, distinct legal regimes have emerged to meet the multiple stakeholders' interests. This article describes the process of fragmentation of the regulatory space based on primary sources, with emphasis on the laws and their preambles, as well as testimonies from those that helped build the regulatory space of the partnerships between the State and OCS. Besides, the paper revisits secondary sources, especially academic papers that analyzed, on different occasions, the construction of this regulatory space. This article contributes to the literature on statenonprofit organizations partnerships insofar as it explains the institutional logics and the underlying social forces of its legal regime.
\end{abstract}

KEYWORDS: Regulatory Space. Partnerships. Civil Society Organizations. State. Third sector.

\footnotetext{
* $\quad$ Professora do Programa de Mestrado em Direito da Regulação da FGV Direito Rio e do curso de graduação da mesma instituição. Doutora e Mestre em Direito pela USP. Master of Laws (LL.M.) pela Yale University. E-mail: natasha.salinas@fgv.br.
} 
PALAVRAS-CHAVE: Espaço Regulatório. Parcerias. Organizações da Sociedade Civil. Estado. Terceiro Setor.

SUMÁRIO: 1 Introdução. 2 A metáfora do espaço regulatório. 3 Espaço regulatório das parcerias entre Estado e OSC. 3.1 A era do marco legal do terceiro setor. 3.2 A era do Marco Regulatório das Organizações da Sociedade Civil. 4 Conclusão. 5 Referências

\section{INTRODUÇÃO}

Diversos são os enfoques possíveis para se caracterizar os modos de interação entre o Estado e as organizações da sociedade civil (OSC). As relações entre atores governamentais e OSC podem ser analisadas, por exemplo, sob a ótica financeira. Nessa perspectiva, o Estado financia, direta e indiretamente, as atividades das OSC. Em termos regulatórios, esses meios de financiamento assumem formas jurídicas variadas, tais como subvenções sociais, imunidades e isenções tributárias, bem como incentivos fiscais a doações.

As relações entre Estado e as OSC podem também ser analisadas sob a lente contratual. Contratos entre entes governamentais e OSC são celebrados para viabilizar a prestação de serviços de interesse público e social em áreas tão variadas como educação, saúde, meio ambiente e assistência social. Para os propósitos deste artigo, adota-se essa última definição de parceria, utilizada para designar as relações entre Estado e OSC mediadas por instrumentos jurídicos de natureza contratual.

O espaço regulatório das parcerias entre Estado e OSC hoje permite oito instrumentos contratuais principais. São eles os convênios, contrato de gestão, termo de parceria, contrato de repasse, termo de colaboração, termo de fomento, acordo de cooperação e termo de compromisso cultural. Cada um desses instrumentos contratuais possui um regime jurídico distinto e varia conforme (a) a natureza do objeto contratual e/ou (b) os tipos de OSC envolvidas.

Sobre a natureza do objeto contratual das parcerias entre Estado e OSC, alguns instrumentos contratuais admitem apenas ações de "interesse público" (e.g., termo de parceria, termo de fomento e termo de colaboração), ao passo que outros contemplam atividades orientadas à satisfação dos interesses mútuos de seus beneficiários (e.g., acordo de cooperação).

Além disso, há divergência entre regimes contratuais sobre o que constitui propriamente uma ação de interesse público ou social. Para alguns, a gratuidade de uma ação é essencial para defini-la como de interesse público (e.g., termo de parceria), ao passo que, para outros, a ação pode até ser onerosa para a população, desde que reverta em benefícios em áreas consideradas socialmente relevantes (e.g., convênio). Há, por fim, aqueles regimes contratuais que, voltados à satis- 
fação do interesse público, aplicam-se apenas a áreas setoriais muito específicas (e.g., contrato de gestão, termo de compromisso cultural).

Quanto aos tipos de organizações qualificadas para celebrar instrumentos contratuais com o Estado, admitem-se apenas entidades sem fins lucrativos voluntariamente constituídas (e.g., termo de parceria, termo de colaboração e termo de fomento), ao passo que para outros aceitam-se organizações cuja criação é estimulada ou regulada pelo Estado (e.g., contrato de gestão do modelo federal). Há, ainda, aqueles instrumentos contratuais que admitem ou rejeitam entidades exclusivamente em função de sua estrutura organizacional, tal como ocorre com as organizações religiosas: a depender do instrumento contratual adotado, uma organização religiosa qualifica (e.g. termo de colaboração, termo de fomento) ou não (e.g. termo de parceria) para celebrar parcerias com o Estado.

Verifica-se, dessa sucinta descrição, que o atual espaço regulatório das parcerias entre Estado e OSC é caracterizado por uma pluralidade de regimes jurídicos que privilegiam determinados atores e temáticas em detrimento de outros. Embora haja uma profusão de estudos descritivos sobre regulação de parcerias entre Estado e OSC no Brasil, poucos trabalhos se debruçam a analisar os fatores condicionantes de sua configuração atual. O objetivo deste artigo é, portanto, explicar porque o espaço regulatório das parcerias entre Estado e organizações da sociedade civil é instável e sobretudo muito fragmentado.

Ver-se-á que o acentuado nível de fragmentação do espaço regulatório das parcerias entre Estado e OSC não é fruto do acaso, tendo sido provocado por disputas entre organizações da sociedade civil e atores estatais sobre as regras que deveriam reger essas parcerias. Diante da impossibilidade de se atingir um consenso sobre as normas que deveriam reger essas parcerias, surgiram regimes legais distintos para atender aos múltiplos interesses em jogo.

Para analisar o espaço regulatório das parcerias entre Estado e OSC, este artigo subdivide-se em duas partes. Na primeira, apresenta-se o conceito teórico de espaço regulatório, utilizado neste artigo para representar metaforicamente a relação dinâmica entre normas e instituições que regulam as parcerias entre Estado e OSC. Na segunda parte do artigo, descreve-se e analisa-se o espaço regulatório das parcerias entre Estado e OSC e suas transformações nas últimas décadas.

O estudo descritivo apresentado na segunda parte foi desenvolvido a partir da análise de fontes primárias, com destaque para a legislação e suas correspondentes exposições de motivos, bem como depoimentos daqueles que marcaram a construção do espaço regulatório das parcerias entre Estado e OSC. Além disso, o artigo revisita fontes secundárias, especialmente artigos e teses que auxiliam na explicação sobre as lógicas institucionais e as forças sociais que regem as parcerias entre Estado e OSC no Brasil. 


\section{A METÁFORA DO ESPAÇO REGULATÓRIO}

A expressão “ambiente" ou "espaço" regulatório foi adotada metaforicamente por Hancher e Moran (1998) para dar ênfase à distribuição de poder regulatório entre organizações distintas. Essa metáfora revela-se importante porque permite reconhecer que atores estatais não possuem monopólio sobre a atividade regulatória.

Reguladores estatais normalmente exercem poder formal no espaço regulatório. A distribuição desse poder entre órgãos estatais, no entanto, pode não respeitar uma estrutura hierarquizada, tal como numa organização burocrática clássica. Além disso, atores não estatais, como agentes regulados, embora não sejam os principais responsáveis pela criação e aplicação de normas regulatórias, podem exercer grande influência sobre elas.

Embora a metáfora do espaço regulatório tenha sido criada por Hancher e Moran (1998) para explicar sistemas regulatórios de países capitalistas avançados, ela também serve para analisar a regulação de outras esferas, como a social desempenhada por organizações da sociedade civil.

A caracterização de um espaço regulatório pressupõe o conhecimento das normas regulatórias e das instituições encarregadas de criá-las, monitorá-las e implementá-las. O espaço regulatório das organizações da sociedade civil, por exemplo, abrange normas sobre isenções tributárias (e.g. isenção de contribuição previdenciária) que determinam quais OSC podem fazer jus a esse benefício e como devem pleiteá-los. Essas normas definem também quais instituições serão encarregadas de conceder (e.g. Ministérios e Secretarias) e fiscalizar (e.g. Receita Federal, tribunais de contas) tais isenções.

Diversos fatores de ordem sociocultural, histórica e organizacional impactam a construção de um espaço regulatório. São esses fatores que explicam a singularidade de um espaço regulatório quando comparado a outros semelhantes.

Um Estado fortemente centralizado e com cultura jurídica formalista tende, por exemplo, a produzir normas altamente hierarquizadas e fortemente procedimentais (e.g., normas de controle de conformidade ${ }^{1}$ que até pouco tempo predominavam no espaço regulatório das parcerias entre Estado e OSC) ${ }^{2}$. Por sua vez, Estados com cultura clientelista e patrimonial são mais propícios ao exercício de poder regulatório informal por parte de agentes privados.

Eventos históricos também impulsionam a construção e modificação do espaço regulatório. Contextos de crise política (e.g., CPI das ONGs no Congresso Nacional) e econômica (crise fiscal e liberalização da economia na década e 1990)

1 Controle de conformidade é aquele que se atém apenas à verificação do cumprimento de normas (e.g. normas sobre procedimentos para gastos dos recursos públicos), e não aos impactos provocados por sua observância ou descumprimento.

2 SALINAS, 2008, p. 97. 
têm catalisado mudanças no espaço regulatório das parcerias entre Estado e OSC no Brasil. No entanto, a compreensão do espaço regulatório pressupõe necessariamente o conhecimento do modo de interação, funcionamento e estrutura das organizações que nele atuam. ${ }^{3}$

O foco nas características organizacionais não negligencia as condicionantes socioculturais e históricas acima mencionadas, já que todas elas se influenciam mutuamente. No entanto, a ênfase nos aspectos organizacionais se dá pelo fato de que a atividade regulatória é realizada por meio de organizações. No presente caso, são as organizações públicas e as organizações da sociedade civil, com suas variadas estruturas e lógicas, que figuram como executoras e alvos da atividade regulatória. Essas organizações influenciam a configuração desse espaço por meio da adesão ou não adesão às normas postas, bem como por meio da pressão para alteração das normas existentes.

Uma característica importante de todo o espaço regulatório é o de que há distribuição - muitas vezes desigual - de poder entre as diferentes organizações que o ocupam. ${ }^{4}$ As interações organizacionais nesse ambiente produzem atores com posição dominante ou central em contraposição a atores que exercem papel coadjuvante ou periférico. A metáfora do espaço regulatório possui, portanto, essa dimensão espacial ou geográfica que permite identificar quem exerce poder - e, portanto, ocupa posição central - e quem subjuga-se a esse poder - ocupando papel periférico - nesse espaço. ${ }^{5}$

Organizações públicas e privadas com diferentes níveis de poder barganham, cooperam e disputam por direitos, prerrogativas e privilégios dentro do espaço regulatório. Aquelas que conseguem articular melhor suas demandas assumem posições privilegiadas nesse espaço e tendem a atuar estrategicamente para manter seu status quo, ao passo que as excluídas do espaço empreenderão esforços para modificá-lo.

Em algumas situações, esses conflitos levarão a uma mudança de posições no espaço regulatório, com perda do status quo para as primeiras e elevação de status para as segundas. Em situações limites, no entanto, onde o esgarçamento dos conflitos não permite uma troca clara de posições, a solução encontrada pode ser a fragmentação ou balcanização das normas que compõem o espaço regulatório.

A compreensão de um espaço regulatório pressupõe, por fim, o conhecimento da cultura organizacional dos atores que nele interagem. A eficácia de um espaço regulatório depende das crenças e percepções das organizações sobre o que pode ser de fato realizado ${ }^{6}$.

\footnotetext{
3 HANCHER; MORAN, 1998, p. 155.

4 SCOTT, 2001, p. 283.

5 HANCHER; MORAN, 1998, p. 154.

6 HANCHER; MORAN:1998, p.163.
} 


\section{ESPAÇO REGULATÓRIO DAS PARCERIAS ENTRE ESTADO E OSC}

O espaço regulatório das parcerias entre Estado e OSC é caracterizado por uma pluralidade de regimes jurídicos. Como já observado, atualmente há nada menos do que oito instrumentos contratuais que o Estado pode celebrar com organizações da sociedade civil para formalizar uma parceria.

O surgimento desses instrumentos contratuais, no entanto, não ocorreu de forma simultânea. As primeiras inovações jurídicas surgiram no final da década de 1990, com a criação de um novo marco legal do terceiro setor. O novo regime, no entanto, não foi capaz de satisfazer os interesses de todas as organizações da sociedade civil, provocando conflitos entre elas.

Os novos regimes acirraram ainda mais as disputas entre organizações da sociedade civil de modo que a solução encontrada foi a de fragmentação das normas do seu espaço regulatório. ${ }^{7} \mathrm{O}$ processo de fragmentação desse espaço será analisado a seguir.

\subsection{A ERA DO MARCO LEGAL DO TERCEIRO SETOR}

A década de 1990 foi marcada por processos de liberalização econômica que impactaram a forma de atuação do Estado na prestação de serviços sociais. Esse foi um período no qual reformas institucionais foram empreendidas, no Brasil e no mundo, para ampliar o volume de contratualização de entidades privadas para a prestação de atividades e serviços de natureza finalística do Estado.

$\mathrm{Na}$ área social, a contratação de organizações privadas para a prestação de serviços finalísticos tinha escopo muito restrito até meados da década de 1990. Os convênios, instrumentos jurídicos de natureza contratual, eram utilizados sobretudo para formalizar acordos de cooperação entre entes federativos (e.g. União e estados), sendo raramente celebrados com as OSC.

A década de 1990 foi marcada, no entanto, por um processo de transformação da regulação das relações entre Estado e organizações privadas. Deu-se início, nos planos nacional e internacional, a um processo de legitimação de reformas administrativas que visavam a diminuir a atuação do Estado no desempenho direto de tarefas públicas.

As Organizações Sociais (OS) surgem neste contexto. O modelo das OS, capitaneado pelo governo federal na tentativa de introduzir uma lógica gerencial no âmbito da Administração Pública, teria um objetivo mais imediato: a reforma das universidades públicas brasileiras, em especial das universidades federais ${ }^{8}$.

O Estado pretendia transformar as universidades públicas, constituídas sob

7 Como visto acima, situações limite de conflitos entre atores provocam a fragmentação ou balcanização do espaço regulatório. HANCHER; MORAN:1998, p.163-164.

8 ALVES, 2002, p. 281. 
a forma de autarquias públicas, em entidades privadas sem fins lucrativos. Essas entidades, por sua vez, passariam a se relacionar com o Estado por meio de uma relação estritamente contratual (o contrato de gestão), na qual se obrigariam a cumprir metas e indicadores em contrapartida a repasses financeiros que seriam realizados periodicamente pelo Estado. Em ao menos um aspecto, essas entidades preservariam a natureza pública: servidores públicos deveriam, obrigatoriamente, atuar de forma permanente em seus conselhos de administração.

Ocorre que, por resistências dentro da comunidade acadêmica e do próprio Ministério da Educação, o processo de descentralização de funções públicas para as OS se deu no âmbito das áreas de ciência e tecnologia, e não da educação. A Lei n. 9.637/98 previu a possibilidade de criação de OS nas áreas de ensino, pesquisa científica, desenvolvimento tecnológico, proteção do meio ambiente, cultura e saúde. No entanto, a estrutura engessada do modelo federal, que exige lei para a criação da OS e requer presença do poder público em suas estruturas de governança, contribuiu para o alcance limitado desse modelo no âmbito federal.

Embora o modelo tenha sido, em sua essência, replicado por diversos estados e municípios da federação brasileira, há significativa variação de arranjos institucionais. Hancher e Moran (1998) observam que a fragmentação regulatória pode ser vista, em grande medida, como um reflexo da própria fragmentação da estrutura federativa de uma determinada comunidade política. No Brasil, os entes federativos têm autonomia para definir o rol de áreas de atuação das organizações sociais com quem celebram contratos de gestão. Isso explica, por exemplo, porque OS da área de educação são admitidas no Estado de Goiás e proibidas no Estado de São Paulo.

Dadas as peculiaridades da relação entre Estado e OS, há quem, do ponto de vista fático e jurídico, não a considere como uma verdadeira parceria. As relações entre Estado e OS são notoriamente induzidas pelo poder público, numa tentativa de delegar (e, para os mais céticos, privatizar) serviços públicos essenciais. A tentativa (frustrada) de declarar a inconstitucionalidade do modelo das OS deve ser compreendida nesse contexto. ${ }^{9}$

De todo modo, o cenário de reforma do Estado que propiciou o surgimento do modelo das Organizações Sociais acabou “dando o tom" às propostas regulatórias que dali adviriam para as relações entre Estado e o terceiro setor. $\mathrm{O}$ tom reformista, na verdade, revelou-se um fenômeno mundial: os excluídos do espaço regulatório das parcerias entre Estado e OSC se aproveitarão desse cenário de mudanças e defenderão a bandeira do fortalecimento da sociedade civil e da participação das OSC na provisão de bens e serviços públicos ${ }^{10}$.

9 Em 2015, o STF manifestou-se pela constitucionalidade da Lei das Organizações Sociais, no âmbito da ADI 1923/DF.

10 INTERNATIONAL CENTER FOR NONPROFIT LAW, 1997. 
No Brasil, as iniciativas de fortalecimento da sociedade civil dos anos 1990 foram capitaneadas por segmentos da sociedade não satisfeitos com o espaço regulatório até então vigente. Atores governamentais (e.g. Conselho de Comunidade Solidária ${ }^{11}$ ), agências de financiamento internacionais (e.g. Banco Interamericano de Desenvolvimento - Bid, UNESCO), comunidade empresarial brasileira (e.g. Grupo de Institutos, Fundações e Empresas - GIFE), universidade brasileira e profissionais do terceiro setor, dentre outros, participaram de diferentes espaços e arenas públicas (e.g. rodadas de articulação política promovidas pelo Conselho da Comunidade Solidária) para promover o que popularmente se denominou de "reforma do marco legal do terceiro setor".

Um marco importante dessa reforma foi a Rodada de Articulação Políti$c a^{12}$ promovida pelo Conselho da Comunidade Solidária no mês de outubro de 1997. Nessa rodada, mais de 90 atores ${ }^{13}$ participaram de uma ampla discussão que culminou na produção de consensos gerais e específicos sobre quais seriam os problemas do marco legal vigente que mereceriam ser erradicados com a reforma.

Um dos consensos específicos ${ }^{14}$ formulados na referida rodada de articulação política pelos aqui denominados champions do marco legal do terceiro setor, foi o de que havia problemas no sistema de registros e certificações. $O$ registro no Conselho Nacional de Seguridade Social CNSS (e, a partir de, 1991, Conselho Nacional de Assistência Social), a obtenção do título de utilidade pública e do certificado de entidade de fins filantrópicos dava ensejo, respectivamente, ao acesso direto a recursos públicos por meio de subvenções sociais e convênios, à concessão de benefícios fiscais a doadores e à isenção do pagamento de contribuição previdenciária.

Esses benefícios, no entanto, eram concedidos discricionariamente a um grupo numericamente pequeno de entidades que ocupavam posição central no

11 O Conselho da Comunidade Solidária foi instituído em 1995 e presidido durante as duas administrações do presidente Fernando Henrique Cardoso (1995-2002) pela primeira-dama Ruth Cardoso. Órgão consultivo da Presidência da República que contava com a participação de ministros de estado e membros da sociedade, o Conselho da Comunidade Solidária exerceu sobretudo o papel de articulador de ideias e de propostas inovadoras de desenvolvimento social, dentre as quais se incluíam o fortalecimento das relações Estado e sociedade civil.

12 As rodadas de articulação política eram realizadas com o objetivo de promover diálogo entre governo e sociedade civil sobre temas sociais estratégicos. Além da reforma do marco legal do terceiro setor, outros temas foram objeto de rodadas de articulação política, como combate à pobreza, expansão do microcrédito, desenvolvimento social integrado e sustentável etc.

13 Participaram desta rodada os membros do Conselho da Comunidade Solidária (10 representantes ministeriais e 10 membros da sociedade) e convidados, notadamente OSC que tinham expressão e atuação nas mais variadas áreas sociais.

14 Os consensos específicos sobre os problemas do marco legal do terceiro setor até então existente foram agrupados nos seguintes temas: (i) registros e cadastros administrativos; (ii) contratos e convênios; (iii) mecanismos de autoregulação; (iv) mecanismos institucionais de responsabilização; (v) doações e a busca de um modelo de financiamento; (vi) regulamentação do voluntariado; (vii) contrato de trabalho por prazo determinado; e (viii) informações. COMUNIDADE SOLIDÁRIA, 1997. 
espaço regulatório. Desse modo, exerciam posição dominante nesse espaço regulatório um número reduzido de entidades que conseguiam transpor as barreiras burocráticas então vigentes. Além disso, o espaço regulatório estava estruturado de modo a excluir um número grande de entidades em função de sua área de atuação, já que os registros e certificações e seus respectivos benefícios eram concedidos apenas às entidades filantrópicas e assistenciais ${ }^{15}$. Paradoxalmente, ao mesmo tempo em que excluía um número considerável de OSC atuantes em prol de interesses coletivos e sociais, a configuração do espaço permitia a entrada de entidades que atuavam apenas em defesa dos interesses mútuos de seus associados (e.g. clubes e associações de categorias profissionais). ${ }^{16}$

Essa é a razão pela qual o regime de incentivos a doações para as OSC também foi elencado como um problema do marco legal do terceiro setor. ${ }^{17}$ Como visto, o marco legal até então vigente atrelava a concessão de incentivos fiscais ao título de utilidade pública (federal $e$ estadual), o que restringia significativamente o acesso das OSC a este benefício.

Um outro problema que foi consensualmente formulado na rodada de interlocução política dizia respeito aos instrumentos jurídicos adotados para formalizar as transferências de recursos públicos às OSC, como subvenções sociais e convênios.

Os convênios eram - e até hoje são - utilizados para reger relações colaborativas em que a instituição concedente (União) transfere recursos públicos a uma instituição convenente (e.g. Estado, Município ou uma OSC) para que esta desenvolva ações e projetos de interesse de ambos. As ações e projetos regidos pelo convênio fazem parte, portanto, de projetos e programas governamentais oficiais.

O convênio, no entanto, passou a ser visto como um instrumento inadequado para reger as relações entre Estado e OSC. Além do problema já mencionado, de que para a celebração de convênios era preciso ter registro no CNSS (e, a partir de 1991, no CNAS), outras ordens de dificuldades foram apontadas, como a discricionariedade na escolha das OSC beneficiárias destes instrumentos e o excessivo formalismo de seu regime jurídico.

Quanto à primeira, o regime jurídico dos convênios, diferentemente daquele aplicado aos contratos administrativos clássicos (que prevê licitação para a escolha da entidade a ser contratada), não exigia, até então, processo seletivo prévio para a escolha da OSC parceira.

Esse padrão discricionário e não-concorrencial - utilizado, na década de 1990, para os convênios celebrados entre Estado e OSC - por não estabelecer

15 COMUNIDADE SOLIDÁRIA, 1997; FERRAREZI, 2001.

16 Este problema foi declarado inclusive na exposição de motivos da então futura Lei 9.790/99, que rege as Organizações da Sociedade Civil. Exposição de Motivos n. 20, de 23 de julho de 1998. Diário da Câmara dos Deputados, 14 out. 1998, p. 23000.

17 MODESTO, 1999, p. 144. 
critérios transparentes, objetivos e claros para a seleção dos projetos e ações sociais que seriam financiados com recursos públicos - foi apontado como um problema a ser erradicado pelos proponentes da reforma do marco legal do terceiro setor.

A segunda ordem de dificuldades identificada no regime dos convênios dizia respeito ao seu excessivo formalismo. Regido pela Constituição (art. 70, parágrafo único e art. 75), pela Lei de Licitação e Contratos (art. 116 da Lei n. $8.666 / 93)^{18}$ e por uma instrução normativa da receita federal (IN n. 1/1997), o convênio possuía regras rígidas de execução financeiro-orçamentária (e.g. rigidez do plano de aplicação de recursos, proibição de uso de verbas do convênio para manutenção e custeio das instituições convenentes).

O convênio era também visto pelos autores da reforma do marco legal do terceiro setor como um instrumento insuficiente para garantir um controle mais efetivo sobre o resultado das ações desempenhadas pelas OSC. As regras que regem os convênios tinham por foco o controle de meios, avaliando o gasto de recursos públicos exclusivamente pelo ponto de vista contábil. Esse controle difere do controle de resultados, que diz respeito ao produto final da parceria.

Os consensos gerados nesse processo de consulta e debates acerca dos problemas a serem erradicados serviram de base para a reforma do marco legal do terceiro setor. Os autores da reforma do marco legal tiveram de optar entre rever a legislação existente - aprimorando a sistemática dos convênios e da outorga dos títulos às OSC - ou criar estatuto novo que coexistisse com aqueles instrumentos. Optou-se por uma lei nova - a lei das OSCIP ${ }^{19}$ - que instituísse um sistema alternativo de outorga de títulos, bem como um novo instrumento de parceria.

Os objetivos declarados pelos autores da Lei das OSCIP eram claros: introduzir um sistema de registro e qualificação das OSC objetivo, transparente e acessível e criar um instrumento contratual focado na realização de resultados e no cumprimento de metas. ${ }^{20}$

Dada a insatisfação das OSC com o sistema de registro e certificação até então vigente, os autores criaram uma qualificação denominada Organização da Sociedade Civil para o Interesse Público ("OSCIP”). ${ }^{21}$ Com essa mudança, alguns dos benefícios anteriormente concedidos pelos outros títulos às OSC passaram a também ser atribuídos às OSCIP. Esse título guardava três diferenças principais em relação aos demais títulos e certificados até então existentes.

18 Antes desses marcos legais, o convênio era regido pelos Decreto-lei n. 2300/86, que antecedeu a Lei n. 8.666/93.

19 Lei n. 9.790, de 23 de março de 1999.

20 Exposição de Motivos n. 20, de 23 de julho de 1998. Diário da Câmara dos Deputados. 14 out. 1998, p. 23000.

21 OSCIP não é forma jurídica, e sim uma qualificação voluntariamente requerida pelas OSC ao Estado e que confere direitos e atribui obrigações às primeiras. 
Em primeiro lugar, os títulos de Utilidade Pública (UP) e o Certificado de Entidade Beneficente de Assistência Social (CEBAS) eram destinados apenas às OSC de assistência social, educação e saúde, ao passo que a qualificação de OSCIP poderia ser conferida a entidades atuantes não apenas nessas áreas tradicionais, mas também em áreas como proteção do meio ambiente, promoção do voluntariado, defesa de direitos, pesquisa científica, dentro outros. ${ }^{22}$ Essa medida visava, portanto, a se aproximar do retrato do perfil das entidades do terceiro setor. Em 2010, havia no Brasil cerca de 290 mil OSC, das quais 30\% atuam na área de defesa de direitos e interesse dos cidadãos, sendo apenas $10 \%$ atuantes na área de assistência social ${ }^{23}$.

Mas a Lei das OSCIP foi além e não disciplinou apenas as áreas abrangidas pelo título (tal como fazia a legislação que disciplina os demais títulos), mas discriminou expressamente os tipos de organizações que não poderiam fazer jus ao título. As entidades de benefício mútuo, por exemplo, cuja atuação se restringe a proporcionar bens ou serviços a um círculo restrito de associados (e.g. clubes e entidades classistas), não poderiam, pela lógica da nova lei, pleitear o título de OSCIP. Essa proibição atendia à já mencionada insatisfação dos defensores da reforma do marco legal com a concessão de benefícios a entidades que, na sua visão, não atendiam a fins públicos ${ }^{24}$.

Para os autores da lei, um dos indicadores de que a atuação da OSC atende a fins públicos é a gratuidade dos serviços que presta. Dessa forma, a lei proibiu expressamente que hospitais e escolas sem fins lucrativos, mas que cobram por seus serviços (e.g. as Pontifícias Universidades Católicas) fossem qualificadas como OSCIP. Para além desse grupo de entidades, a lei proibiu a concessão do título a instituições religiosas, sindicatos e partidos políticos, incluindo as fundações por estes criadas.

A escolha por especificar quais tipos de entidades fariam jus ao título e seus correspondentes benefícios tinha o objetivo de restringir a discricionariedade do poder público na concessão do título. O UP e o CEBAS eram concedidos a um grupo ínfimo de entidades que conseguia transitar pelos meandros da burocracia estatal. Das mais de 250 mil OSC existentes em 2006, somente cerca de 11 mil possuíam o título de Utilidade Pública Federal, 8 mil possuíam CEBAS e 17 mil possuíam registro no $\mathrm{CNAS}^{25}$.

Com a edição da Lei das OSCIP, pretendeu-se introduzir um sistema ágil, simples, objetivo e de amplo alcance. Desse modo, qualquer entidade considerada, pela lógica da lei, de “interesse público" passou a ter o direito de requerer o título

22 Art. 3. Da Lei n. 7.790, de 23 de março de 1999.

23 INSTITUTO BRASILEIRO DE GEOGRAFIA E ESTATÍSTICA;IPEA, 2012.

24 Exposição de Motivos n. 20, de 23 de julho de 1998. Diário da Câmara dos Deputados. 14 out. 1998, p. 23000.

25 EDELMANN, 2013, p. 82. 
de OSCIP, o qual não poderia ser negado imotivadamente pelo poder público. ${ }^{26}$

O OSCIP também se diferenciou dos títulos anteriores pelos mecanismos de responsabilização e de controle que estavam a ele atrelados. Para serem qualificadas como OSCIP, as entidades devem seguir um regime de organização e funcionamento que, na visão dos autores da lei, fortalecia a transparência e responsabilização dos seus atos. A obrigatoriedade de possuir conselho fiscal e o dever de prestar contas periodicamente ao órgão concedente figuram entre estes mecanismos. Por fim, o título de OSCIP diferenciou-se dos demais porque passou a habilitar as OSC assim qualificadas a celebrar uma nova modalidade de contrato com o poder público - o termo de parceria.

O termo de parceria foi concebido para ser um instrumento contratual diferente do convênio. Uma das inovações foi a previsão do concurso de projetos, uma espécie de processo seletivo prévio, para a seleção das OSCIP parceiras. Sua adoção foi prevista como facultativa ${ }^{27}$, mas a legislação estabeleceu exigências mínimas (e.g. especificações técnicas do objeto, critérios de seleção, composição da comissão julgadora etc.) para quando esse fosse utilizado.

A introdução de metas e indicadores nas cláusulas do termo de parceria tornou-se também obrigatória. O trabalho das comissões de monitoramento e avaliação do termo de parceria, que se tornaram obrigatórias, passou a ser orientado por essas métricas. Procurou-se, com essas medidas, introduzir uma cultura de avaliação de resultados nas parcerias entre Estado e OSC, inexistente, como já observado, no regime dos convênios.

Além disso, as regras de execução financeiro-orçamentária tornaram-se mais flexíveis no novo instrumento. As OSCIP estavam autorizadas, por exemplo, a adotar regulamento próprio para a contratação de bens e serviços de terceiros pagos com recursos do termo de parceria, enquanto que as entidades que celebravam convênio estavam obrigadas à época a seguir a lei de licitações. As OSCIP podiam também utilizar parte dos recursos do termo de parceria na sua própria manutenção (e.g. pagamento de empregados e custeio de despesas administrativas), algo que era proibido no regime dos convênios.

Essas foram algumas das inovações introduzidas pelo regime do termo de parceria que incorporaram parte das reivindicações formuladas sob o manto

26 A legislação previu expressamente no art. 1. par. 2, que a concessão do título é ato vinculado ao cumprimento de certas exigências legais. $\mathrm{O}$ decreto que regulamentou a lei também inovou ao suprimir qualquer lapso temporal entre o momento do indeferimento da concessão do título e a reapresentação do pedido de qualificação. Um pedido indeferido de UPF, por exemplo, só poderia ser reapresentado 2 anos após a decisão de indeferimento (art. 3, par. 3., do Decreto n. 3.100/99).

27 A obrigatoriedade de processo seletivo prévio só se tornou obrigatória recentemente para a celebração do termo de colaboração e termo de fomento - instrumentos contratuais previstos no novo Marco Regulatório das Organizacões da Sociedade Civil (MROSC). O termo de parceria manteve-se sempre facultativo, permitindo que órgãos públicos contratassem as mesmas OSCIP repetidas vezes. TREZZA, 2007, p. 1999. 
da bandeira "reforma do marco legal do terceiro setor". Esse novo regime, no entanto, não teve força suficiente para promover uma mudança estrutural no espaço regulatório das parcerias entre Estado e OSC. Inexistia, à época, “consenso político suficiente sobre os rumos do Terceiro Setor" ${ }^{28}$. A solução foi, portanto, realizar "uma mudança gradual e focalizada" ${ }^{29}$ : a aprovação da Lei das OSCIP não revogou a legislação sobre convênios, tampouco alterou o regime de concessão dos títulos de UP e CEBAS. Entidades portadoras desses títulos mais tradicionais, inclusive, optaram por mantê-los ao invés de migrar para o novo modelo de OSCIP.

Verifica-se, aqui, um certo isomorfismo institucional no qual as organizações mantêm-se no formato anterior, visto como mais legítimo por diversos atores inseridos no espaço regulatório, sem perder o caráter de novidade ${ }^{30}$. Embora importantes segmentos da sociedade estivessem envolvidos no projeto de reforma do marco legal do terceiro setor, ficaram de fora dele, como visto, uma série de organizações que já se encontravam em posição privilegiada nesse espaço regulatório.

O trabalho dos promotores do novo discurso do terceiro setor, os empreendedores do processo de inovação legal, foi, portanto, rejeitado por outros atores que conseguiam fazer valer sua força dentro do espaço regulatório. Organizações religiosas, sindicatos, partidos políticos e suas fundações, um grande número de hospitais e escolas e suas mantenedoras, como observado, não foram consideradas entidades "legítimas" pelos proponentes da Lei das OSCIP. Por outro lado, essas entidades já faziam jus a uma série benefícios (e.g, imunidade tributária, incentivos fiscais para doadores, possibilidade de recebimento de subvenções sociais) que não pretendiam perder com a reforma do marco legal do terceiro setor. Para essas entidades, ilegítimo era o processo de construção do marco legal do terceiro setor, que as deixava de fora.

A estratégia das OSC “antigas” foi a de barganhar, por meio de pressão parlamentar (e.g. bancada religiosa), para que as reformas em curso não extinguissem o regime antigo que lhes beneficiava: elas aceitaram não oferecer resistência à nova lei, conquanto que não revogasse o conjunto de normas que lhes beneficiava. ${ }^{31}$

De outro lado, os proponentes da reforma do marco legal aceitaram a proposta de coexistência de regimes, dentre outros motivos, porque uma proposta de revogação da legislação então vigente comprometeria as condições de aprovação da nova lei.

\footnotetext{
28 FALCÃO; CUENCA, 1999, p. 31.

29 FALCÃO; CUENCA, 1999, p. 31.

30 ALVES, 2002, p. 138.

31 FERRAREZI, 2001, p. 9-10.
} 
Além disso, a opção por reformar a legislação existente de modo a construir um regime único para todas as OSC implicaria atingir um consenso, à época inatingível, entre OSC muito distintas. $\mathrm{Na}$ visão dos proponentes da Lei das OSCIP, seus interesses estariam comprometidos se esta se estendesse à totalidade das OSC, já que os objetivos da reforma do marco legal do terceiro setor, conforme visto, consistiam no reconhecimento e fortalecimento de um grupo particular de organizações. ${ }^{32}$

A estratégia, no entanto, de aceitar a “pulverização” ou fragmentação do espaço regulatório teve efeitos perversos, sobretudo para os proponentes da Lei das OSCIP. Em primeiro lugar, o novo regime de parcerias atraiu um número bem menor do que o esperado de OSC. Os benefícios proporcionados pela nova lei não foram percebidos como suficientemente atrativos para as entidades que já detinham os títulos de UP e CEBAS, a quem foi dada a possibilidade de migrar para o novo regime em até dois anos da aprovação da lei.

No momento em que a Lei das OSCIP foi aprovada, não foi dada a possibilidade às entidades detentoras dessa qualificação de receber doações dedutíveis do imposto de renda das pessoas jurídicas (esse benefício só foi concedido em 2001) e a isenção de pagamento da contribuição previdenciária jamais foi concedido, até hoje, a outras entidades que não as portadoras do CEBAS. "O contexto de forte ajuste fiscal da época não permitiu condições mínimas para negociação de incentivos fiscais específicos para as OSCIP" ${ }^{3}$.

Já para as OSC que não possuíam registros e certificações, o título de OSCIP foi também percebido como pouco atrativo porque além de exigir mecanismos mais rígidos de controle (e.g. necessidade de prestação de contas anual ao Ministério da Justiça) e oferecer poucos benefícios fiscais, não trazia a garantia de celebração do termo de parceria. Como será visto na seção seguinte, a prática de celebração do termo de parceria não atingiu a eficácia esperada.

Como visto, a Lei das OSCIP procurou introduzir uma lógica "gerencial” na gestão das parcerias entre Estado e OSC. Isso implicaria, no entanto, uma mudança na cultura organizacional não só das OSC, mas sobretudo dos entes estatais. Isso porque os órgãos técnicos e jurídicos responsáveis pela gestão e controle do termo de parceria eram os mesmos encarregados de administrar os convênios.

$\mathrm{Na}$ prática, muitas das normas engessadas dos convênios eram aplicadas sem adaptações na gestão e controle dos termos de parceria (e.g. consultoria jurídica não recomendando a utilização dos recursos do termo de parceria para custeio de empregados da OSCIP - algo permitido pela Lei das OSCIP e proibido pela legislação dos convênios). ${ }^{34}$

32 FERRAREZI, 2001, p. 9-10.

33 TREZZA, 2007, p. 105.

34 TREZZA, 2007, p. 91-107. 
Além disso, algumas medidas de flexibilização que o regime do termo de parceria procurou introduzir foram reputadas, sobretudo pelos órgãos de controle (e.g. tribunais de contas), como incompatíveis com o sistema jurídico vigente. Um exemplo ilustra a questão: o regulamento da lei das OSCIP (Decreto n. 3.100/99), em seu art. 23, previu a possibilidade de que o termo de parceria fosse utilizado para a contratação de serviços de consultoria, cooperação técnica e assessoria das OSC. O Tribunal de Contas da União (TCU) considerou, no entanto, que o termo de parceria não poderia ser utilizado para a contratação dessas atividades, que reputou como "atividades-meio.” Temendo represálias dos órgãos de controle (e.g. tribunais de contas), os gestores públicos continuaram “presos” à lógica de gestão dos convênios, focada, como visto, na análise de conformidade das atividades-meio, e não das atividades-fim dos projetos desenvolvidos por meio de parcerias entre Estado e OSC.

Por fim, os gestores públicos, em sua grande maioria, não estavam capacitados para empreender uma avaliação de resultados dos termos de parceria, a qual exigiria a aplicação de metodologias para a construção e análise de metas e indicadores de projetos. A Lei das OSCIP, além disso, era vaga quanto às formas de interação entre órgãos públicos e as OSC na avaliação de resultados, o que gerou insegurança entre os gestores ${ }^{35}$ e deu margem a práticas pouco uniformes de gestão destas parcerias ${ }^{36}$.

Os pontos de vista dos gestores encarregados de aplicar a Lei das OSCIP condicionaram, portanto, o modo como essa foi de fato implementada. No presente caso, essas percepções contribuíram para a total ineficácia do instrumento. Os órgãos gestores, podendo optar por qualquer dos dois instrumentos contratuais (algo permitido em um espaço regulatório fragmentado) rapidamente deixaram de adotar o instrumento e passaram a celebrar convênios com as OSC, inclusive aquelas qualificadas como OSCIP.

Desse modo, a Lei das OSCIP teve um destino completamente inesperado: ela não só introduziu um mecanismo de parceria ineficaz, mas também contribuiu para a expansão do uso do convênio, que passou a ser celebrado com OSC de todas as áreas sociais. ${ }^{37}$ De 2009 a 2013 a União celebrou 110 termos de parcerias com OSCIP contra 8.808 convênios com OSC ${ }^{38}$.

Apesar de todas as suas limitações, o convênio era percebido como um instrumento mais conciliador (dada a falta de consenso sobre as áreas que devem ser priorizadas com as parcerias entre Estado brasileiro e OSC), mais democrático (já que incluía OSC de variados tipos) e mais adaptado à cultura organizacional

35 TREZZA, 2007, p. 95.

36 KOGA, 2004, p. 134.

37 O convênio, em sua concepção original, era celebrado apenas com entidades sem fins lucrativos com registro no CNSS/CNAS.

38 SECRETARIA GERAL DA PRESIDÊNCIA DA REPÚBLICA, 2015, p. 93. 
das OSC do que o termo de parceria. Com o passar dos anos, o instituto do convênio foi sofrendo modificações que contribuíram para o alastramento do seu uso. A adoção de contratos de repasse para reger as parcerias entre Estado e OSC, a partir de $2006^{39}$, se inseriu neste contexto.

Contrato de repasse é um instrumento de parceria muito similar ao convênio, porém que se distingue por ser administrado por um mandatário da União (normalmente uma instituição financeira oficial, como a Caixa Econômica Federal) que detém melhores condições de acompanhar a execução de projetos que envolvam alguma obra de engenharia, especialmente em razão de sua proximidade física e capacitação técnica. As normas aplicáveis aos convênios também o são para os contratos de repasse, de modo que o crescimento do primeiro instituto contribuiu para a adoção do segundo nas parcerias entre Estado e OSC.

Em 2007, o poder executivo federal determinou, por meio do Decreto n. 6.170/07, que todo projeto que envolvesse a realização de obra deveria ser regido por contrato de repasse. Algumas OSC, por exemplo, passaram a ser contratadas pelo governo federal por meio de contrato de repasse para desenvolver tecnologias de inovação social (e.g. cisternas para captação de água para consumo familiar em regiões do semi-árido). No entanto, a grande maioria das parcerias entre Estado e OSC permaneceria, até dezembro de $2015,{ }^{40}$ regida pelos convênios. De 2009 a 2014, mais de $60 \%$ dos repasses de recursos públicos para particulares foi feito por meio de convênios ${ }^{41}$.

\subsection{A ERA DO MARCO REGULATÓRIO DAS ORGANIZAÇÕES DA SOCIEDADE CIVIL}

Não obstante as tentativas de aperfeiçoamento do regime do convênio, a percepção de que esse era um instrumento inadequado para disciplinar as parcerias entre Estado e OSC só cresceu com o passar dos anos. Além dos problemas já mencionados, outros foram sendo evidenciados à medida que o convênio se tornava o instrumento principal das parcerias. Um deles era o fato de que esse instrumento era disciplinado por um emaranhado de normas que, em função do seu caráter infralegal, possuíam pouca estabilidade.

Num intervalo de apenas dez anos, as OSC que celebrassem convênio com a União para adquirir bens e serviços com recursos públicos tiveram que adotar (i) procedimentos análogos aos estabelecidos na Lei de Licitações (entre

39 O contrato de repasse tornou-se aplicável às parcerias com OSC com o advento da Lei de Diretrizes Orçamentárias de 2006 (Lei n. 11.178, de 20 de setembro de 2005).

40 Essa é a data em que o Marco Regulatório das Organizações da Sociedade Civil (MROSC) entrou efetivamente em vigor, com a promulgação da Lei n. 13.204, de 14 de dezembro de 2015.

41 SECRETARIA GERAL DA PRESIDÊNCIA DA REPÚBLICA, 2015, p. 93. 
1997 e $2003^{42}$ ), (ii) pregão eletrônico (de 2005 A 200743) e cotação prévia (de 2007 a $2016^{44}$ ).

As sucessivas mudanças na legislação dos convênios provocaram também insegurança quanto a sua aplicação. Estudos empíricos evidenciaram que havia divergência de interpretação sobre as normas dos convênios não apenas entre os órgãos (e.g. um ministério permitindo e outro proibindo despesas de custeio das OSC com verba do convênio), ${ }^{45}$ mas no interior de uma única organização (uma secretaria aprovando despesas de custeio no momento da celebração do convênio e glosando tal despesa posteriormente na fase de prestação de contas).

Além disso, embora o convênio fosse o instrumento jurídico predominante, seu regime tratava apenas das relações entre Estado e OSC envolvendo repasse de recursos como contrapartida à realização de tarefas de finalidade pública. Outros mecanismos de sustentabilidade econômica das OSC ainda eram de alcance de um número restrito de entidades.

O recebimento de doações dedutíveis do imposto de renda de pessoas jurídicas, por exemplo, só estava ao alcance das OSC portadoras do UP e, a partir de 2001, do título de OSCIP. Como visto, a adesão à qualificação de OSCIP foi menor do que a esperada, de modo que o recebimento de doações dedutíveis do imposto de renda permanecia restrito a um número sub-representativo de entidades.

É nesse contexto que surge, a partir de 2010, o movimento reformista denominado "Plataforma por um Novo Marco Regulatório das Organizações da Sociedade Civil”, articulado por OSC, redes e movimentos sociais. Em resposta a essa articulação, diversos atores governamentais, liderados pela Secretaria Geral da Presidência da República e por organizações da sociedade civil de representatividade nacional, compuseram um grupo interministerial que trabalhou ativamente na produção de novos estudos sobre os problemas do espaço regulatório das parcerias entre Estado e OSC.

Alguns dos problemas diagnosticados pelo grupo de trabalho no regime dos convênios já eram velhos conhecidos, como ausência de lei específica (dado o regime infralegal dos convênios), instabilidade regulatória, pouca ênfase no controle de resultados, falta de capacidade institucional para a gestão das parcerias etc. Outros, eram problemas eram novos, como a dificuldade de adaptação às normas do Sistema Eletrônico de Convênios - Siconv ${ }^{46}$.

42 IN STN 01/97.

43 Decreto n. 5.504/05.

44 Decreto n. 6.170/07.

45 Estudo realizado por Grupo Interministerial encarregado de formular projeto de lei sobre o Marco Regulatório das Organizações da Sociedade Civil identificou, no âmbito federal, 14 instrumentos normativos permitindo a remuneração de empregados das OSC, 12 proibindo e 59 se omitindo a este respeito. SECRETARIA GERAL DA PRESIDÊNCIA DA REPÚBLICA, 2015 , p. 7.

46 SECRETARIA GERAL DA PRESIDÊNCIA DA REPÚBLICA, 2014, p. 6. 
O Marco Regulatório das Organizações da Sociedade Civil (MROSC) foi instituído pela Lei n. 13.019 de 31 de julho de 2014. Essa lei previu uma vacatio legis de três meses, período que permitiu às organizações resistentes às mudanças para se articularem e pressionarem pela prorrogação da lei. A lei foi prorrogada duas vezes por meio de medidas provisórias ${ }^{47}$ e teve o seu texto original significativamente alterado pela Lei n. 13.204, de 14 de dezembro de $2015 .^{48}$

Diferentemente do movimento protagonista da reforma do marco legal do terceiro setor dos anos 1990, o movimento pelo novo Marco Regulatório defendeu a edição de uma lei abrangente - de alcance nacional e válida para um grupo extenso de organizações. Distanciando-se da lógica da Lei das OSCIP, o MROSC estabeleceu um conceito de Organização da Sociedade Civil suficientemente abrangente para englobar todas as entidades sem fins lucrativos, independentemente da área de atuação. Incluiu, ainda nesse conceito, as organizações religiosas prestadoras de serviços na área social e as cooperativas sociais.

O MROSC, em sua versão modificada pela Lei n. 13.204/15, previu incentivos fiscais para toda e qualquer pessoa jurídica interessada em doar recursos financeiros às OSC regidas pela nova lei. ${ }^{49}$ No entanto, o MROSC não previu incentivos fiscais para doações provenientes de pessoas físicas, os quais permaneceram sendo apenas admitidos no âmbito de áreas setoriais muito específicas, como esporte, criança e adolescente, idoso, etc.

Essa inovação legal coincidiu com a extinção do título de Utilidade Pública em nível federal. Sendo o seu principal benefício justamente a concessão de incentivos fiscais aos potenciais doadores, esse título perdeu utilidade com a edição do MROSC.

O MROSC introduziu ainda, desde a sua versão original, três novos tipos contratuais que substituiriam o convênio na regulação das parcerias entre Estado OSC: o termo de colaboração, o termo de fomento e o acordo de cooperação.

Denominou-se de termo de colaboração o instrumento que tem por objetivo disciplinar uma parceria entre Estado e OSC cujo objeto decorre de uma demanda estatal (e.g. município que contrata organizações prestadoras de serviço de creche). Já o termo de fomento é o instrumento contratual que visa a reger parcerias cujo objeto decorra de uma proposta formulada espontaneamente pela OSC. Por fim, acordo de cooperação é o instrumento pelo qual são formalizadas parcerias entre Estado e OSC que não envolvam transferência de recursos públicos.

47 A Medida Provisória n. 684/2014 prorrogou por um ano a entrada em vigor da Lei n. 13.019/14. Já a Medida Provisória n. 685/2014 adiou a entrada em vigor da lei por mais seis meses. Esta última medida provisório foi ainda modificada ao se converter no Projeto de Lei de Conversão n 21, de 2015, que terminou por estabelecer prazo de entrada em vigor escalonado para a lei: 23 de janeiro de 2016 para União, Estados e DF e janeiro de 2017 para municípios.

48 A Medida Provisória n. 685/2015 recebeu 152 emendas de 39 parlamentares.

$49 \mathrm{O}$ art. $84 \mathrm{~B}$ da nova lei previu a possibilidade de dedução de até $2 \%$ da receita bruta das empresas doadoras para fins de apuração do imposto de renda. 
A instituição de dois tipos contratuais distintos - termo de colaboração e termo de fomento - foi a solução encontrada para a variabilidade dos modos de interação entre Estado e OSC. No termo de colaboração, é a Administração Pública que determina os objetivos e as metas que deverão ser alcançados com a parceria, bem como exerce papel preponderante na determinação dos seus meios de execução. No termo de fomento, é a OSC que propõe à Administração um projeto ou atividade e seu curso de ação, cabendo à última financiar essa atividade.

O MROSC instituiu regimes semelhantes para formalizar ambas as modalidades de parcerias. Para ambas há a necessidade de chamamento público prévio (para a escolha da OSC parceira), comissão de monitoramento e avaliação dos projetos, prestação de contas com foco no controle de resultados, etc.

O MROSC teria se tornado uma norma de alcance amplo e universal, se não fosse pelo fato de que dele foram excluídas: (i) as entidades qualificadas como Organizações Sociais que celebram contrato de gestão com a Administração Pública; (ii) as entidades qualificadas como OSCIP que celebram termo de parceria com o Estado; (iii) as entidades filantrópicas que prestam serviços de saúde, continuaram celebrando convênios com a Administração Pública; (iv) as entidades culturais que celebram termo de compromisso cultural com o poder executivo.

Além disso, a lei do MROSC dispensou de uma série de suas exigências (e.g. obrigatoriedade de chamamento público) todas as OSC das áreas de assistência, saúde e educação.

$\mathrm{O}$ que explica essas exceções que contribuíram para a manutenção (ou até mesmo intensificação) da fragmentação do espaço regulatório das parcerias entre Estado e OSC?

Durante as sucessivas prorrogações da lei n. 13.019/14, que só entrou em vigor quase dois anos após sua publicação ${ }^{50}$, ela foi significativamente alterada de modo a acomodar as diversas forças e interesses em jogo. Embora os defensores do MROSC tenham se orgulhado do caráter mobilizador e participativo da construção da lei, fato é que dele não participaram, ou não se sentiram contempladas, diversas OSC que já se relacionavam com o Estado.

Diferentemente do Marco Legal do Terceiro Setor, o Marco Regulatório das Organizações da Sociedade Civil tinha pretensões universalistas. O Marco Legal do Terceiro Setor dos anos 1990 criou regime paralelos sem desconstruir os demais existentes. Já o MROSC tinha a pretensão de estabelecer um regime único para essas entidades.

50 O MROSC entrou em vigor para as administrações federal e estaduais em janeiro de 2016, um ano e meio após a aprovação da Lei n. 13.019/14. Para as administrações municipais, o MROSC entrou em vigor apenas em janeiro de 2017, dois anos após a aprovação da lei que o originou. 
Essa tentativa, no entanto, fracassou: as OSC que se viram prejudicadas diante das transformações do espaço regulatório não tiveram outra saída a não ser intervir no processo legislativo em curso. Raras vezes se viu, na história legislativa brasileira, uma lei ser tão profundamente modificada, meses após sua promulgação. Esse é um fato que não pode ser negligenciado e que tem muito a revelar sobre as forças condicionantes do processo de fragmentação do espaço regulatório entre Estado e OSC.

Abaixo segue tabela descrevendo o retrato atual do espaço regulatório das parcerias entre Estado e OSC.

\begin{tabular}{|c|c|c|}
\hline ATORES & INSTRUMENTO & NORMAS \\
\hline $\begin{array}{l}\text { Todas as entidades sem fins } \\
\text { lucrativos, independentemente } \\
\text { da forma jurídica } \\
\text { A partir de } 2016 \\
\text { Apenas as entidades } \\
\text { assistenciais que prestam } \\
\text { serviços ao SUS }\end{array}$ & Convênio & $\begin{array}{l}\text { CF (arts. } 70 \text { e } 75 \text { ) } \\
\text { Lei n. } 8.666 / 93 \text { (art. 116) } \\
\text { IN n. 1/1997 } \\
\text { Decreto n. 6.170/07 } \\
\text { Portaria Interm. n. } \\
\text { 127/2008 Portaria } \\
\text { Interm. n. 424/2016 }\end{array}$ \\
\hline $\begin{array}{l}\text { Todas as entidades sem fins } \\
\text { lucrativos, independentemente } \\
\text { da forma jurídica (a partir da } \\
\text { LDO de 1996) } \\
\text { A partir de } 2016 \\
\text { Apenas as entidades } \\
\text { assistenciais que prestam } \\
\text { serviços ao SUS }\end{array}$ & Contrato de Repasse & $\begin{array}{l}\text { Normas do convênio } \\
\text { Decreto n. } 1.819 / 96\end{array}$ \\
\hline $\begin{array}{l}\text { Entidades portadoras do título } \\
\text { de OSCIP } \\
\text { Áreas de atuação } \\
\text { - Proteção ao Meio } \\
\text { - Ambiente; } \\
\text { Promoção do } \\
\text { - Voluntariado; } \\
\text { - } \quad \text { Defesa de Direitos } \\
\text { - } \quad \text { Paúde, educaçãão e } \\
\quad \text { assistência social. }\end{array}$ & Termo de Parceria & $\begin{array}{l}\text { Lei n. } 9.790 / 99 \\
\text { Decreto n. 3.100/99 }\end{array}$ \\
\hline
\end{tabular}




\begin{tabular}{|c|c|c|}
\hline $\begin{array}{l}\text { Entidades Qualificadas como } \\
\text { Organizações Sociais (OS) } \\
\text { Áreas de atuação (modelo } \\
\text { federal) } \\
\text { - Ensino } \\
\text { - Pesquisa Científica } \\
\text { - Desenvolvimento } \\
\text { - Tecnológico } \\
\text { - Proteção do Meio } \\
\text { - Ambiente } \\
\text { - Sultura }\end{array}$ & Contrato de Gestão & Lei n. 9.637/98 \\
\hline $\begin{array}{l}\text { Todas as entidades sem fins } \\
\text { lucrativos } \\
\text { Cooperativas Sociais }\end{array}$ & $\begin{array}{ll}\text { o } & \begin{array}{l}\text { Termo de } \\
\text { Colaboração } \\
\text { o }\end{array} \\
\text { Termo de } \\
\text { Fomento } \\
\text { o } & \begin{array}{l}\text { Acordo de } \\
\text { Cooperação }\end{array}\end{array}$ & $\begin{array}{l}\text { Lei n. } 13.019 / 14 \\
\text { Decreto n. } 8.726 / 16\end{array}$ \\
\hline Entidades da área de cultura & $\begin{array}{l}\text { Termo de } \\
\text { Compromisso } \\
\text { Cultural }\end{array}$ & $\begin{array}{l}\text { Lei n }{ }^{\circ} 13.018 / 2014 \\
\text { IN MinC n. 01/2015 }\end{array}$ \\
\hline
\end{tabular}

Fonte: elaboração própria.

\section{CONCLUSÃO}

Neste trabalho, procurou-se descrever os processos de transformação e de fragmentação do espaço regulatório das parcerias entre Estado e OSC ao longo do tempo.

Até 1990, esse espaço foi marcado pela predominância de normas de fomento que se traduziam na concessão discricionária de benefícios pelo poder público a um grupo restrito de OSC. Esses benefícios, em sua maioria atrelados à concessão de títulos e certificações, eram concedidos a entidades em função de seus atributos organizacionais, e não em razão dos projetos e ações sociais que elas desempenhavam. Os atores que ocupavam posição privilegiada no espaço regulatório desse período eram poucos, atuavam em áreas tradicionais de filantropia e possuíam notória desenvoltura para perpetrar os meandros da burocracia estatal.

De 1990 em diante, assistiu-se a uma expressiva transformação no espaço regulatório ora examinado, de tal modo que as normas que previam ações de fomento cederam espaço para normas de contratação de serviços públicos desempenhados por OSC. As OSC que se encontravam na periferia do espaço regulatório e, que, portanto, não se beneficiavam do regime jurídico de fomento até então vigente foram as principais empreendedoras dessas mudanças. Essas 
OSC reivindicaram a introdução de critérios isonômicos, de meritocracia, representatividade e legitimidade para celebrarem contratos com o Estado.

Por outro lado, aqueles atores que se perceberam ameaçados com inovações jurídicas dessa natureza adotaram estratégias de blindagem para garantir a manutenção de seus privilégios no espaço regulatório. A estratégia de barganhar pela manutenção do regime antigo a despeito da introdução de um regime novo foi a tônica que marcou o processo de desenvolvimento do espaço regulatório das OSC.

Esse fenômeno se repetiu mesmo com a tentativa de instituição de um novo regime jurídico de caráter universalizante - o Marco Regulatório das Organizações da Sociedade Civil. Esse objetivo totalizante do MROSC já nasceu frustrado, diante do bem sucedido movimento de diversas organizações para afastar-se dele.

O espaço regulatório foi, portanto, balcanizado pelas organizações da sociedade civil que o compõe. Neste artigo, procurou-se demonstrar como e porque esse processo de fragmentação do espaço regulatório ocorreu.

\section{REFERÊNCIAS}

ALVES, M. A. Terceiro Setor: o dialogismo polêmico. (Tese de Doutorado). São Paulo. Escola de Administração de Empresas de São Paulo da Fundação Getulio Vargas, 2002.

\section{COMUNIDADE SOLIDÁRIA. $6^{\circ}$ Rodada de Interlocução Política do}

Conselho da Comunidade Solidária. Documento. 06 out 1997.

EDELMANN, Rafael de Oliveira Batista. Um caso de barreira burocrática - UPF e CEBAS até a Lei n. 12.101/2009. Revista de Direito do Terceiro Setor, vol. 7, n. 14, p. 71-90, jul/dez. 2013, p. 71-89.

FALCÃO, Joaquim; CUENCA, Carlos. Diretrizes para nova legislação do terceiro setor. In: FALCÃO, Joaquim; CUENCA, Carlos (Orgs). Mudança Social e Reforma Legal: estudos para uma nova legislação do terceiro setor. Brasília: Conselho da Comunidade Solidária: UNESCO: BID: FBB, 1999, p. 19-53.

FERRAREZI, E. O novo marco legal do terceiro setor no Brasil. Atualização do trabalho apresentado no III Encuentro de la Red Latinoamericana y del Caribe de la Sociedad Internacional de Investigación del Tercer Sector (ISTR) - Perspectivas Latinoamericanas sobre el Tercer Sector, 2001, Buenos Aires (Argentina). Disponível em: <www.lasociedadcivil.org/uploads/ciberteca/ferrarezi. pdf>. Acesso em: 19/10/2018.

HANCHER, L; MORAN; M. Organizing Regulatory Space. In: BALDWIN, Robert et al. (Orgs). A Reader on Regulation. Oxford: Oxford University Press, 1998. 
INSTITUTO BRASILEIRO DE GEOGRAFIA E ESTATÍSTICA;IPEA. As Fundações Privadas e Associações sem Fins Lucrativas no Brasil 2010. Rio de Janeiro, 2012. Acesso em: 10/04/2019.

KOGA, Natália Massaco. As Organizações da Sociedade Civil de Interesse Público (OSCIPS) e o Termo de Parceria: uma reflex sobre a relação entre Estado e Sociedade Civil. Dissertação (Mestrado em Administração) - Escola de Administração de Empresas de São Paulo, Fundação Getulio Vargas, São Paulo, 2004, 179 p.

INTERNATIONAL CENTER FOR NONPROFIT LAW. Marco Regulador de las Organizaciones de la Sociedad Civil en Sudamérica. 1997. Disponível em: <http:// www.icnl.org/library/lamerica/docs/sabook2.html>. Acesso em: 10 out. 2007.

MODESTO, Paulo. Reforma do marco legal do terceiro setor. In: FALCÃO, Joaquim; CUENCA, Carlos (Orgs). Mudança Social e Reforma Legal: estudos para uma nova legislação do terceiro setor. Brasília: Conselho da Comunidade Solidária: UNESCO: BID: FBB, 1999, p. 139-156.

SALINAS, Natasha Schmitt Caccia. Avaliação Legislativa no Brasil: um estudo de caso de caso sobre as normas de controle das transferências voluntárias de recursos públicos para entidades do terceiro setor. Dissertação (Mestrado em Direito) - Faculdade de Direito da Universidade de São Paulo, São Paulo, 2008, $256 \mathrm{p}$.

SCOTT, Colin. Analysing Regulatory Space: fragmented resources and institutional design. Public Law, p. 283-305, 2001.

SECRETARIA GERAL DA PRESIDÊNCIA DA REPÚBLICA. Marco Regulatório das Organizações da Sociedade Civil: a construção da agenda no governo federal - 2011 a 2014. Brasília, 2015. Disponível em: < http://www.secretariadegoverno. gov.br/iniciativas/mrosc/publicacoes>. Acesso em: 10/04/2019.

TREZZA, Valéria Maria. O termo de parceria como instrumento de relação público/privado sem fins lucrativos: o difícil equilíbrio entre flexibilidade e controle. Dissertação (Mestrado em Administração) - Escola de Administração de Empresas de São Paulo, Fundação Getulio Vargas, 2007, 199p.

Recebido em: 15/04/2019.

Aprovado em: 24/09/2019. 


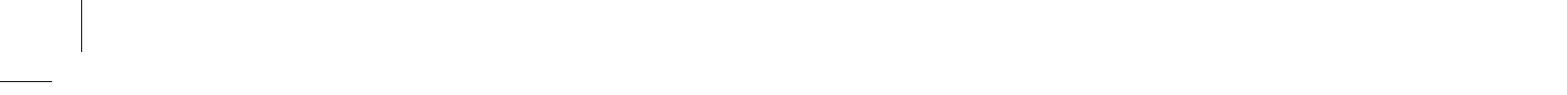

